\title{
Potensi dan strategi pengelolaan berkelanjutan mata air Sikumbang di Desa Pulau Sarak Kecamatan Kampar Kabupaten Kampar
}

\author{
Arif Hidayatullah ${ }^{1}$, Rifardi $^{2}$, Sigit Sutikno ${ }^{3}$ \\ ${ }^{1}$ Pascasarjana Ilmu Lingkungan Program Pascasarjana Universitas Riau \\ ${ }^{2}$ Fakultas Perikanan dan Ilmu Kelautan Universitas Riau \\ ${ }^{3}$ Fakultas Teknik Universitas Riau Universitas Riau \\ *Correspondent email : arifajoyo@gmail.com
}

\begin{abstract}
In 2019 there were 9 (nine) managers of drinking water from Sikumbang Springs. The management of the Sikumbang Spring water supply business is still carried out individually and traditionally means that the management carried out by the Sikumbang Spring entrepreneur is only limited to exploitation. Management does not include environmental preservation. The purpose of this study was to determine the potential and determine the sustainable management strategy of Sikumbang Springs in Pulau Sarak Village, Kampar District, Kampar Regency. The benefit gained from this research is the balance between environmental, economic and social aspects in managing Sikumbang Spring. and the community as water users / entrepreneurs get information on the potential of Sikumbang Springs in Pulau Sarak Village. Analysis of the projected population of each village in the Kampar subdistrict above can be calculated the number of residents who use clean water. The more accurate results of the largest population is at the end of the planned year, namely in 2029 with a total population of 50.732 people (10-year projection). The potential of Sikumbang Spring based on the value of its debit from March to December 2020 is 247.127.040 liters. The need for clean water for household needs (drinking and cooking water) in Kampar sub-district is 6,3 ((liters / day) / soul), so that the community's water demand in Kampar sub-district in 2019 is 310.697 liters / day. The average daily debit of Sikumbang Springs is 808.272 liters / day. The calculation of the average daily debit of Sikumbang Spring shows that the debit value of Sikumbang Spring exceeds the value of its needs. Therefore, Sikumbang Springs in the study area can be used as an alternative in meeting the water needs of the local community and communities outside Pulau Sarak Village. Based on the results of the SWOT analysis of the management of the Sikumbang Spring, the strategy that can be applied is an aggressive (development) strategy that is maximizing strengths and taking advantage of available opportunities, so as to minimize weaknesses and avoid threats. Sikumbang Spring management must optimize the main function of Sikumbang Spring as a source of clean water in meeting household water needs and improving its marketing system. The role of the community in maintaining and preserving the source of the Sikumbang Spring also needs to be enhanced.
\end{abstract}

Keyword : water potency; water required; strategy management water

Air merupakan sumber daya alam yang mutlak dibutuhkan dalam kehidupan manusia di bumi, sehingga kehidupan manusia tidak akan dapat dipisahkan dari air. Pada masa yang akan datang seiringan dengan pertambahan penduduk, maka kebutuhan manusia terhadap air meningkat dari waktu ke waktu. Pemenuhan kebutuhan pangan dan aktivitas penduduk selalu erat kaitannya dengan kebutuhan akan air bersih. Sejalan dengan bertambahnya kebutuhan air bersih, maka bermunculan usaha penyediaan air bersih oleh perusahaan air minum. Berdasarkan data BPS Provinsi Riau (2017), selama periode 2011-2015 sumber air baku terbesar yang digunakan oleh perusahaan air minum adalah air sungai dan sumber air baku terkecil yang digunakan oleh perusahaan air minum adalah mata air. Rata-rata pertumbuhan produksi air minum yang bersumber dari mata air di Provinsi Riau Tahun 2011 - 2015 menunjukkan terjadinya penurunan (Tabel 1).

Tabel 1. Produksi Perusahaan Air Bersih menurut Sumber Air yang digunakan di Provinsi Riau Tahun 2011 - 2015 $\left(\mathrm{m}^{3}\right)$

\begin{tabular}{lrrrrr}
\hline \multirow{2}{*}{ Sumber Air } & \multicolumn{5}{c}{ Tahun } \\
\cline { 2 - 6 } & \multicolumn{1}{c}{2011} & \multicolumn{1}{c}{2012} & \multicolumn{1}{c}{2013} & \multicolumn{1}{c}{2014} & 2015 \\
\hline Sungai & 18.379 .597 & 18.381 .882 & 18.493 .991 & 19.097 .691 & 21.135 .293 \\
Waduk & 397.333 & 399.764 & 399.958 & 388.771 & 358.028 \\
Mata Air & 297.658 & 298.027 & 299.958 & 242.559 & 74.592 \\
Lainnya & 989.700 & 990.986 & 993247 & 1.171 .085 & 1.380 .765 \\
\hline Jumlah & 20064288 & 20.070 .659 & 20.187 .154 & 20.900 .106 & 22.948 .678 \\
\hline
\end{tabular}

Sumber : BPS Provinsi Riau, 2017 


\section{ZONA}

Jurnal Lingkungan

ISSN : 2502-6496 (Print)

Desa Pulau Sarak Kecamatan Kampar Kabupaten Kampar memiliki sumber air bersih yang dikenal dengan nama Mata Air Sikumbang yaitu mata air yang bersumber dari Hutan Larangan Adat Kenegerian Rumbio Desa Pulau Sarak. Mata Air Sikumbang dieksploitasi oleh masyarakat sebagai sumber air bersih untuk usaha air minum dalam memenuhi kebutuhan air rumah tangga masyarakat Desa Pulau Sarak maupun masyarakat yang berasal dari daerah di luar Desa Pulau Sarak seperti Air Tiris, Bangkinang dan Pekanbaru. Hidayat (2015) menjelaskan bahwa terdapat 8 (delapan) pengelola mata air Sikumbang yang total debit airnya sebesar 8,992 liter/detik. Dari semua pengelola itu bisa menjual 103.500 jerigen air perbulan, dan tiap jerigennya bervolume 30 liter air. Kelembagaan dalam pemanfaatan mata air Sikumbang di Desa Pulau Sarak belum ada dilakukan secara formal. Sampai saat ini untuk pemanfaatan dan pengelolaan mata air Sikumbang masih dilakukan secara individu. Winasari (2015) menyatakan air yang bersumber dari mata air Sikumbang Desa Pulau Sarak Kecamatan Kampar telah terkontaminasi oleh Koliform. Penyebab kontaminasi bakteri Koliform dipengaruhi oleh letak geografis sumber mata air dan cara pengaliran air dari sumber. Para pengelola air minum mengalirkan air dari sumbernya melalui sambungan pipa-pipa melewati perkebunan masyarakat hingga ketempat pendistribusian, panjang pipapipa tersebut lebih kurang $2 \mathrm{~km}$, pipa-pipa tersebut memiliki ketebalan 2,5 inchi dan pada saat pemasangan pertama pipa-pipa tersebut tidak ada yang dicuci hamakan terlebih dahulu.

Pada Tahun 2019 jumlah usaha air minum Mata Air Sikumbang menjadi 9 (sembilan) pengelola. Pengelolaan usaha air minum Mata Air Sikumbang masih dilakukan secara individu dan bersifat tradisional serta hanya sebatas eksploitasi saja. Pengelolaannya belum mencakup kepada pemeliharaan lingkungan. Apabila Mata Air Sikumbang hanya dieksplotasi saja tanpa adanya usaha-usaha pemeliharaan, maka seiring bertambah waktu akan terjadi penurunan kuantitas dan kualitas dari Mata Air Sikumbang. Oleh sebab itu, perlu adanya upaya memelihara keberlanjutan sumber daya Mata Air Sikumbang agar tersedia dalam kuantitas dan kualitas yang memenuhi syarat baku air minum, baik pada waktu sekarang maupun yang akan datang.

Berdasarkan penjelasan di atas, informasi mengenai kuantitas dan kualitas air yang dihasilkan dari ke sembilan Mata Air Sikumbang belum tersedia secara detil. Maka perlu dilakukan penelitian mengenai potensi dan strategi pengelolaan berkelanjutan Mata Air Sikumbang di Desa Pulau Sarak Kecamatan Kampar Kabupaten Kampar. Tujuan penelitian ini adalah mengetahui potensi dan menentukan strategi pengelolaan berkelanjutan Mata Air Sikumbang di Desa Pulau Sarak Kecamatan Kampar Kabupaten Kampar. Manfaat yang diperoleh dari penelitian ini adalah adanya keseimbangan antara aspek lingkungan, ekonomi, dan sosial dalam mengelola Mata Air Sikumbang. dan masyarakat sebagai pemakai/pelaku pengusaha air mendapatkan informasi potensi Mata Air Sikumbang yang ada di Desa Pulau Sarak Kecamatan Kampar Kabupaten Kampar.

\section{METODA PENELITIAN}

Pendekatan penelitian yang digunakan dalam penelitian ini adalah metode survei dilakukan melalui beberapa tahap yaitu tahapan survei, tahapan pengumpulan (wawancara dan kuesioner) dan pengolahan data, serta tahapan perhitungan dan analisis data. Jenis data yang dikumpulkan dalam penelitian ini terdiri dari data primer dan data sekunder. Data primer yang dikumpulkan adalah data kuantitas dan kualitas Mata Air Sikumbang. Data kuantitas Mata Air Sikumbang terdiri dari data debit Mata Air Sikumbang diperoleh dengan menggunakan metode volumetrik. Data kualitas Mata Air Sikumbang diketahui dengan cara uji laboratorium. Data sekunder adalah data yang diperoleh secara tidak langsung dari lapangan berupa literatur kualitas air, peta-peta daerah penelitian Mata Air Sikumbang, data demografi (jumlah penduduk, tingkat pendidikan, dan luas wilayah) Desa Pulau Sarak, dan data usaha Mata Air Sikumbang.

Pengukuran debit Mata Air Sikumbang dilakukan dengan metode volumetrik. Langkah-langkah pengukuran debit mata air Sikumbang dengan metoda volumetrik sebagai berikut :

1. Alat tampung ember yang volumenya 5 liter.

2. Stop watch untuk mengukur waktu

3. Diperlukan 3 (tiga) orang untuk melakukan pengukuran. Satu orang untuk memegang alat tampung, satu orang bertugas mengoperasikan stop watch, dan orang ketiga melakukan pencatatan.

4. Proses dimulai dengan aba-aba dari orang pemegang stop watch pada saat penampungan air dimulai, dan selesai ketika alat tampung sudah terisi penuh. Pengukuran dilakukan sebanyak 3 (tiga) kali ulangan. Waktu yang diperlukan mulai dari awal penampungan air sampai terisi penuh dicatat dalam form pengukuran. 


\section{ZONA}

Jurnal Lingkungan

ISSN : 2502-6496 (Print)

Pengukuran suhu Mata Air Sikumbang dilakukan dengan menggunakan termometer air raksa yang mempunyai skala sampai $110{ }^{\circ} \mathrm{C}$ sesuai SNI 06-6989.23-2005. Prinsip kerja termometer air raksa sesuai SNI 06-6989.23-2005 adalah air raksa dalam termometer akan memuai atau menyusut sesuai dengan panas air yang diperiksa, sehingga suhu air dapat dibaca pada skala termometer $\left({ }^{\circ} \mathrm{C}\right)$. Langkah-langkah pelaksanaan pengukuran suhu Mata Air Sikumbang sesuai SNI 06-6989.23-2005 sebagai berikut :

1. Termometer langsung dicelupkan ke dalam contoh uji dan biarkan 2 menit sampai dengan 5 menit sampai termometer menunjukkan nilai yang stabil.

2. Catat pembacaan skala termometer tanpa mengangkat lebih dahulu termometer dari air

Pengukuran derajat keasaman $(\mathrm{pH})$ Mata Air Sikumbang dilakukan dengan menggunakan $\mathrm{pH}$ meter sesuai SNI 06-6989.11-2004. Langkah-langkah pelaksanaan pengukuran derajat keasaman (pH) Mata Air Sikumbang sesuai SNI 06-6989.11-2004 sebagai berikut :

1. Keringkan dengan kertas tisu selanjutnya bilas elektroda dengan air suling.

2. Bilas elektroda dengan contoh uji.

3. Celupkan elektroda ke dalam contoh uji sampai $\mathrm{pH}$ meter menunjukkan pembacaan yang tetap.

4. Catat hasil pembacaan skala atau angka pada tampilan dari $\mathrm{pH}$ meter.

Pengukuran kualitas air parameter mikrobiologi (total koliform) Mata Air Sikumbang dilakukan dengan menggunakan penyaring membran (membrane filter) sesuai SNI 3554:2015. Prinsip kerja uji koliform dengan menggunakan penyaring membran yaitu menyaring sampel yang hendak diuji menggunakan penyaring membran (membrane filter) yang mampu menjerat mikroorganisme, kemudian meletakkan penyaring membran tersebut pada permukaan cawan agar chromogenic coliform kemudian menginkubasi penyaring membran pada suhu $(36 \pm 2){ }^{\circ} \mathrm{C}$ selama $(21 \pm 3)$ jam. Langkah-langkah pelaksanaan pengujian koliform Mata Air Sikumbang sesuai SNI 3554:2015 sebagai berikut :

1. Sampel air diambil dari Mata Air Sikumbang

2. Pasang peralatan penyaring membran yang telah disterilkan dan hubungkan dengan pompa vakum. Masukkan $100 \mathrm{ml}$ sampel ke dalam corong dari alat penyaring dan saring sampel seluruhnya dengan menyalakan pompa vakum. Bilas seluruh permukaan dalam corong penyaring dengan air suling steril yang jumlahnya sama dengan jumlah contoh yang disaring, saring cairan pembilas, dan hentikan vakum.

3. Buka kembali peralatan penyaring, dengan pinset yang steril angkat membran dari alat penyaring. Letakkan membran di atas cawan petri yang berisi Chromogenic Coliform Agar (CCA), pastikan tidak terdapat gelembung udara yang terperangkap di bawah penyaring membran. Inkubasi cawan petri dengan posisi terbalik pada suhu $(36 \pm 2)^{\circ} \mathrm{C}$ selama $(21 \pm 3)$ jam.

4. Hitung semua koloni berwarna merah muda hingga merah yang negatif oksidase sebagai bakteri koliform. Hitung semua koloni berwarna biru tua hingga ungu sebagai bakteri E. Coli. Untuk memastikan koloni berwarna merah muda hingga merah adalah bakteri koliform harus dilakukan uji konfirmasi oksidase menggunakan Bactidant Oxidase.

5. Ambil semua koloni yang berwarna merah muda hingga merah atau sedikitnya 10 koloni dan goreskan ke kertas Bactidant Oxidase, tunggu sampai 30 detik. Jika berubah menjadi ungu berarti oksidase positif (non koliform), jika warna tidak berubah (tetap merah muda hingga merah) berarti oksidase negatif.

6. Total bakteri koliform adalah jumlah seluruh koloni berwarna merah muda hingga merah yang negatif oksidase sebagai bakteri koliform. Hitung semua koloni berwarna biru tua hingga ungu sebagai bakteri E. Coli. Nyatakan hasil dalam satuan koloni per $100 \mathrm{ml}$ (koloni/100 ml).

Analisis data kualitas air dalam penelitian ini adalah dengan uji koliform di laboratorium, sedangkan analisis data yang dikumpulkan melalui wawancara dan kuesioner digunakan untuk dasar analisis strategi dengan menggunakan Analisis SWOT. Selanjutnya analisis data kuantitas Mata Air Sikumbang diperoleh dari perhitungan debit air Mata Air Sikumbang menggunakan rumus sebagai berikut (Widodo, 2017) :

$$
\mathrm{Q}=V / t
$$

Keterangan :

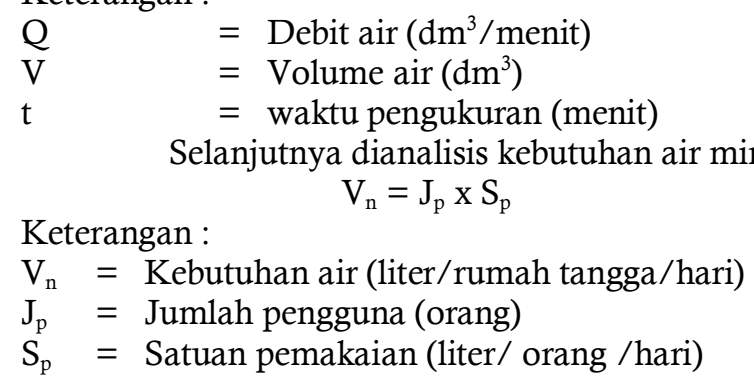


Selanjutnya dianalisis imbangan pemanfaatan air rumah tangga dengan besarnya debit mata air. Analisis imbangan pemanfaatan air rumah tangga ini dapat diketahui beradasarkan perhitungan sebagai berikut:

Keterangan :

$$
\begin{gathered}
\mathrm{I}_{\mathrm{RT}}=\mathrm{Q}_{\mathrm{T}}-\mathrm{V}_{\mathrm{T}} \\
\mathrm{V}_{\mathrm{T}}=\mathrm{V}_{\mathrm{n}} \times \mathrm{N} \\
\mathrm{QT}=\mathrm{Q} \times 3600 \times 24
\end{gathered}
$$

$\mathrm{I}_{\mathrm{RT}}=$ Imbangan air rumah tangga (liter/hari)

$\mathrm{Q}_{\mathrm{T}}=$ Debit total mata air (liter/hari)

$\mathrm{V}_{\mathrm{T}}=$ Pemanfaatan air total (liter/hari)

$\mathrm{V}_{\mathrm{n}}=$ Kebutuhan air (liter/rumah tangga/hari)

$\mathrm{N}=$ Jumlah rumah tangga $(\mathrm{KK})$

$\mathrm{Q}=$ Debit mata air (liter/detik)

Pada tahapan untuk menentukan strategi pengelolaan berkelanjutan Mata Air Sikumbang digunakan analisis SWOT dari hasil wawancara narasumber, selanjutnya dilakukan identifikasi variabelvariabel eksternal berupa peluang dan ancaman serta variabel-variabel internal berupa kekuatan dan kelemahan dalam pengelolaan Mata Air Sikumbang. Variabel strategi pengelolaan Mata Air Sikumbang Desa Pulau Sarak Kecamatan Kampar Kabupaten Kampar dapat dilihat pada Tabel 2.

Tabel 2. Variabel Strategi Pengelolaan Mata Air Sikumbang Desa Pulau Sarak Kecamatan Kampar Kabupaten Kampar

\begin{tabular}{llrll}
\hline \multicolumn{1}{c}{ VARIABEL } & \multicolumn{2}{c}{ KONSEP } & \multicolumn{1}{c}{ INDIKATOR } & \multicolumn{1}{c}{ TEKNIK PENGUMPULAN } \\
DATA
\end{tabular}

\section{HASIL DAN PEMBAHASAN}

Desa Pulau Sarak secara geografis berada pada koordinat 0o19'36" LU - 0o20'47" LU sampai dengan 101o7'28" BT - 101o8'21" BT. Desa Pulau Sarak memiliki batas-batas wilayah sebagai berikut: sebelah Utara berbatasan dengan Desa Rumbio Kecamatan Kampar, sebelah Selatan berbatasan dengan Desa Sungai Upai Kecamatan Gunung Sahilan, sebelah Barat berbatasan dengan Desa Penyasawan Kecamatan Kampar, dan sebelah Timur berbatasan dengan Desa Rumbio Kecamatan Kampar. Jumlah penduduk Desa Pulau Sarak pada tahun 2019 adalah sebanyak 1707 jiwa yang terdiri dari laki-laki berjumlah 819 jiwa dan perempuan berjumlah 888 jiwa. Penyebaran penduduk Desa Pulau Sarak ini terbagi ke dalam $407 \mathrm{KK}$. Pada penelitian ini, uji kualitas air dilakukan pada sembilan titik sampel Mata Air Sikumbang yang digunakan sebagai sumber air bersih untuk air minum masyarakat desa Pulau Sarak dan desa di luar Pulau Sarak. Adapun hasil uji parameter fisik, kimia, dan biologi kualitas air Mata Air

\begin{tabular}{|c|c|c|c|c|c|c|c|c|c|c|c|c|}
\hline \multirow{2}{*}{ No } & \multirow{2}{*}{ Parameter } & \multirow{2}{*}{ Satuan } & \multicolumn{9}{|c|}{ Hasil Sampel } & \multirow{2}{*}{$\begin{array}{l}\text { Baku } \\
\text { Mutu }\end{array}$} \\
\hline & & & I & II & III & IV & $\mathrm{V}$ & VI & VII & VIII & IX & \\
\hline & \multicolumn{12}{|l|}{ A. Fisika } \\
\hline 1. & Suhu & ${ }^{\circ} \mathrm{C}$ & 27 & 26 & 27 & 27 & 26 & 26 & 26 & 27 & 26 & $\begin{array}{c} \pm 3 \text { dari } \\
\text { suhu } \\
\text { ruanga } \\
\mathrm{n}\end{array}$ \\
\hline 2. & Bau & - & $\begin{array}{c}\text { Tidak } \\
\text { Berbau }\end{array}$ & $\begin{array}{c}\text { Tidak } \\
\text { Berbau }\end{array}$ & $\begin{array}{c}\text { Tidak } \\
\text { Berbau }\end{array}$ & $\begin{array}{c}\text { Tidak } \\
\text { Berbau }\end{array}$ & $\begin{array}{l}\text { Tidak } \\
\text { Berbau }\end{array}$ & $\begin{array}{c}\text { Tidak } \\
\text { Berbau }\end{array}$ & $\begin{array}{c}\text { Tidak } \\
\text { Berbau }\end{array}$ & $\begin{array}{c}\text { Tidak } \\
\text { Berbau }\end{array}$ & $\begin{array}{l}\text { Tidak } \\
\text { Berbau }\end{array}$ & $\begin{array}{c}\text { Tidak } \\
\text { Berbau }\end{array}$ \\
\hline \multirow[t]{2}{*}{3.} & Rasa & - & Normal & Normal & Normal & Normal & Normal & Normal & Normal & Normal & Normal & $\begin{array}{c}\text { Tidak } \\
\text { Berasa }\end{array}$ \\
\hline & B. Kimia & & & & & & & & & & & \multirow{3}{*}{$6,5-8,5$} \\
\hline 4. & $\mathrm{pH}$ & - & 6,9 & 6,9 & 6,9 & 6,9 & 6,9 & 7,1 & 7,1 & 6,9 & 7,1 & \\
\hline & C. Biologi & & & & & & & & & & & \\
\hline 5. & $\begin{array}{l}\text { Total } \\
\text { Koliform }\end{array}$ & $\begin{array}{c}\text { jumlah } \\
/ 100 \\
\mathrm{ml}\end{array}$ & 9 & 2 & 13 & 5 & 3 & 0 & 1 & 7 & 0 & 0 \\
\hline
\end{tabular}
Sikumbang Desa Pulau Sarak dapat dilihat pada Tabel 3.

Tabel 3. Hasil Uji Parameter Fisik, Kimia, dan Biologi Kualitas Air Mata Air Sikumbang 


\section{ZONA}

Jurnal Lingkungan

ISSN : 2502-6496 (Print)

Hasil uji kualitas air Mata Air Sikumbang dengan parameter fisik menunjukkan hasil adalah tidak berbau dan rasa normal. Hal ini menyebabkan masyarakat selalu ingin mengkonsumsi air tanpa memasak terlebih dahulu atau langsung diminum. Hasil pemeriksaan pada parameter biologis Mata Air Sikumbang di atas, menunjukkan adanya cemaran bakteri Koliform pada beberapa sumber Mata Air Sikumbang. Keadaan tersebut menunjukkan bahwa Mata Air Sikumbang belum memenuhi syarat kesehatan untuk langsung diminum karena mengandung bakteri koliform. Menurut Peraturan Menteri Kesehatan republic Indonesia Nomor 492/MENKES/PER/IV/2010 tentang persyaratan Kualitas Air Minum untuk bakteri koliform adalah dalam jumlah per $100 \mathrm{ml}$ sampel adalah 0 (nol). Oleh sebab itu, penggunaan Mata Air Sikumbang untuk air minum harus diolah terlebih dahulu dengan cara memasaknya.

Analisis ketersediaan air Mata Air Sikumbang dilakukan dengan pendekatan umum yaitu data jumlah debit ketersediaan air Mata Air Sikumbang yang didapat dari hasil pengamatan. Hasil perhitungan ketersediaan air Mata Air Sikumbang di Desa Pulau Sarak dapat dilihat pada Tabel 4.

Tabel 4. Hasil Pengukuran Debit Harian dan Debit Bulanan Mata Air Sikumbang Bulan Maret Desember 2019

\begin{tabular}{clcc}
\hline No. & \multicolumn{1}{c}{ Bulan } & Debit Harian (liter/hari) & Debit Bulanan (liter/bulan) \\
\hline 1. & Maret 2019 & 685.440 & 21.248 .640 \\
2. & April 2019 & 806.400 & 24.192 .000 \\
3. & Mei 2019 & 732.960 & 22.721 .760 \\
4. & Juni 2019 & 862.560 & 25.876 .800 \\
5. & Juli 2019 & 715.680 & 22.186 .080 \\
6. & Agustus 2019 & 648.000 & 20.088 .000 \\
7. & September2019 & 757.440 & 22.723 .200 \\
8. & Oktober 2019 & 892.800 & 27.676 .800 \\
9. & November 2019 & 1.010 .880 & 30.326 .400 \\
10. & Desember 2019 & 970.560 & 30.087 .360 \\
\hline
\end{tabular}

Dari Tabel 4 diketahui bahwa debit harian Mata Air Sikumbang yang terbesar terjadi di bulan November 2019 dengan debit 1.010.880 liter/hari. Debit harian Mata Air Sikumbang yang terkecil terjadi di bulan Agustus 2019 dengan debit 648.000 liter/hari. Ketersediaan Mata Air Sikumbang yang terbesar terjadi di bulan November 2019 dengan debit 30.326.400 liter/bulan. Ketersediaan Mata Air Sikumbang yang terkecil terjadi di bulan Agustus 2019 dengan debit 20.088.000 liter/bulan.

Analisis kebutuhan air bersih dilakukan adalah untuk mengetahui seberapa besar potensi Mata Air Sikumbang dalam memenuhi kebutuhan air bersih. Sebelum melakukan analisis kebutuhan air bersih, maka tahap pertama adalah melakukan perhitungan mengenai proyeksi jumlah penduduk di wilayah kecamatan Kampar. Analisis proyeksi jumlah penduduk di wilayah kecamatan Kampar direncanakan sampai 10 tahun yang akan datang terhitung dari Tahun 2020 sampai Tahun 2029. Data jumlah penduduk yang digunakan untuk menghitung rerata pertumbuhan penduduk adalah data jumlah penduduk masingmasing desa di Kecamatan Kampar dari Tahun 2015 sampai dengan Tahun 2019. Data jumlah penduduk Kecamatan Kampar Tahun 2015 - 2019 dapat dilihat pada Tabel 5.

Tabel 5. Jumlah Penduduk Kecamatan Kampar Tahun 2015 - 2019

\begin{tabular}{|c|c|c|c|c|c|c|}
\hline \multirow{2}{*}{ No. } & \multirow{2}{*}{ Desa / Kelurahan } & \multicolumn{5}{|c|}{ Jumlah Penduduk (jiwa/tahun) } \\
\hline & & 2015 & 2016 & 2017 & 2018 & 2019 \\
\hline 1 & Air Tiris & 6362 & 6377 & 6391 & 6399 & 6405 \\
\hline 2 & Batu Belah & 5008 & 5028 & 5038 & 5045 & 5058 \\
\hline 3 & Tanjung Berulak & 2211 & 2222 & 2228 & 2235 & 2241 \\
\hline 4 & Ranah & 3431 & 3440 & 3452 & 3458 & 3460 \\
\hline 5 & Penyasawan & 5397 & 5409 & 5417 & 5426 & 5428 \\
\hline 6 & Rumbio & 3298 & 3306 & 3312 & 3321 & 3331 \\
\hline 7 & Padang Mutung & 2803 & 2811 & 2820 & 2829 & 2836 \\
\hline 8 & Pulau Jambu & 1536 & 1542 & 1549 & 1552 & 1557 \\
\hline 9 & Tanjung Rambutan & 2324 & 2333 & 2345 & 2356 & 2362 \\
\hline 10 & Simpang kubu & 2465 & 2477 & 2486 & 2496 & 2508 \\
\hline
\end{tabular}




\begin{tabular}{llccccc}
11 & Naumbai & 2003 & 2009 & 2013 & 2018 & 2023 \\
12 & Limau Manis & 2138 & 2147 & 2158 & 2162 & 2168 \\
13 & Ranah Singkuang & 1120 & 1125 & 1133 & 1139 & 1144 \\
14 & Ranah Baru & 1100 & 1104 & 1107 & 1112 & 1119 \\
15 & Bukit Ranah & 2069 & 2072 & 2079 & 2083 & 2091 \\
16 & Pulau Sarak & 1679 & 1684 & 1691 & 1698 & 1707 \\
17 & Pulau Tinggi & 1728 & 1732 & 1739 & 1746 & 1756 \\
18 & Koto Tibun & 2090 & 2103 & 2111 & 2115 & 2123 \\
\hline & Jumlah & 48762 & 48921 & 49069 & 49190 & 49317 \\
\hline
\end{tabular}

Sumber: Kecamatan Kampar Tahun 2019

Proyeksi jumlah penduduk untuk setiap desa pada wilayah Kecamatan Kampar menggunakan perhitungan yang sama seperti pada perhitungan untuk Desa Pulau Sarak. Hasilnya dapat dilihat pada 6.

Tabel 6. Proyeksi Jumlah Penduduk Setiap Desa Pada Wilayah Kecamatan Kampar

\begin{tabular}{|c|c|c|c|c|c|c|c|c|c|c|c|c|}
\hline \multirow{2}{*}{ No. } & \multirow{2}{*}{ Desa } & \multicolumn{11}{|c|}{ Proyeksi jumlah penduduk setiap desa pada wilayah Kecamatan Kampar } \\
\hline & & 2019 & 2020 & 2021 & 2022 & 2023 & 2024 & 2025 & 2026 & 2027 & 2028 & 2029 \\
\hline 1 & Air Tiris & 6405 & 6416 & 6427 & 6437 & 6448 & 6459 & 6470 & 6481 & 6492 & 6503 & 6514 \\
\hline 2 & Batu Belah & 5058 & 5071 & 5083 & 5096 & 5108 & 5121 & 5134 & 5147 & 5160 & 5172 & 5185 \\
\hline 3 & Tanjung Berulak & 2241 & 2249 & 2256 & 2264 & 2271 & 2279 & 2287 & 2294 & 2302 & 2310 & 2318 \\
\hline 4 & Ranah & 3460 & 3467 & 3475 & 3482 & 3489 & 3497 & 3504 & 3511 & 3519 & 3526 & 3534 \\
\hline 5 & Penyasawan & 5428 & 5436 & 5444 & 5451 & 5459 & 5467 & 5475 & 5483 & 5491 & 5498 & 5506 \\
\hline 6 & Rumbio & 3331 & 3339 & 3348 & 3356 & 3364 & 3373 & 3381 & 3390 & 3398 & 3406 & 3415 \\
\hline 7 & Padang Mutung & 2836 & 2844 & 2853 & 2861 & 2869 & 2878 & 2886 & 2895 & 2903 & 2912 & 2920 \\
\hline 8 & Pulau Jambu & 1557 & 1562 & 1568 & 1573 & 1578 & 1584 & 1589 & 1594 & 1600 & 1605 & 1611 \\
\hline 9 & Tanjung Rambutan & 2362 & 2372 & 2381 & 2391 & 2401 & 2410 & 2420 & 2430 & 2440 & 2450 & 2460 \\
\hline 10 & Simpang kubu & 2508 & 2519 & 2530 & 2541 & 2552 & 2563 & 2574 & 2585 & 2596 & 2608 & 2619 \\
\hline 11 & Naumbai & 2023 & 2028 & 2033 & 2038 & 2043 & 2048 & 2053 & 2058 & 2064 & 2069 & 2074 \\
\hline 12 & Limau Manis & 2168 & 2176 & 2183 & 2191 & 2198 & 2206 & 2214 & 2222 & 2229 & 2237 & 2245 \\
\hline 13 & Ranah Singkuang & 1144 & 1150 & 1156 & 1162 & 1169 & 1175 & 1181 & 1187 & 1194 & 1200 & 1206 \\
\hline 14 & Ranah Baru & 1119 & 1124 & 1129 & 1133 & 1138 & 1143 & 1148 & 1153 & 1158 & 1163 & 1168 \\
\hline 15 & Bukit Ranah & 2091 & 2097 & 2102 & 2108 & 2113 & 2119 & 2124 & 2130 & 2136 & 2141 & 2147 \\
\hline 16 & Pulau Sarak & 1707 & 1714 & 1721 & 1728 & 1735 & 1743 & 1750 & 1757 & 1764 & 1772 & 1779 \\
\hline 17 & Pulau Tinggi & 1756 & 1763 & 1770 & 1777 & 1784 & 1792 & 1799 & 1806 & 1813 & 1821 & 1828 \\
\hline 18 & Koto Tibun & 2123 & 2131 & 2140 & 2148 & 2157 & 2165 & 2173 & 2182 & 2191 & 2199 & 2208 \\
\hline & & $\begin{array}{c}4931 \\
7\end{array}$ & $\begin{array}{c}4945 \\
7\end{array}$ & $\begin{array}{c}4959 \\
7\end{array}$ & $\begin{array}{c}4973 \\
7\end{array}$ & $\begin{array}{c}4987 \\
8\end{array}$ & $\begin{array}{c}5002 \\
0\end{array}$ & $\begin{array}{c}5016 \\
1\end{array}$ & $\begin{array}{c}5030 \\
3\end{array}$ & $\begin{array}{c}5044 \\
6\end{array}$ & $\begin{array}{c}5058 \\
9\end{array}$ & $\begin{array}{c}5073 \\
2\end{array}$ \\
\hline
\end{tabular}

Dari analisis proyeksi jumlah penduduk setiap desa pada wilayah Kecamatan Kampar di atas dapat dihitung jumlah penduduk pengguna air bersih. Untuk mendapatkan hasil yang lebih akurat diambil jumlah penduduk terbesar yaitu pada akhir tahun rencana proyeksi yaitu pada Tahun 2029 dengan total jumlah penduduk 50.732 jiwa (proyeksi 10 tahun), maka sesuai Tabel 2.1 Kecamatan Kampar termasuk dalam kategori "kota kecil" dengan jumlah penduduk berkisar 20.000-100.000 jiwa.

Analisis potensi Mata Air Sikumbang untuk kebutuhan air rumah tangga diperoleh dari hasil perhitungan antara kebutuhan air rumah tangga dengan jumlah penduduk. Kebutuhan air rumah tangga yang akan dibahas dalam penelitian ini merupakan kebutuhan air rumah tangga air minum dan memasak dalam suatu rumah tangga. Data yang diperlukan untuk menghitung jumlah kebutuhan air rumah tangga setiap desa di wilayah Kecamatan Kampar yaitu data jumlah penduduk dan standar kebutuhan air rumah tangga yang akan digunakan. Jumlah kebutuhan air rumah tangga (air minum dan memasak) saat ini di Desa Pulau Sarak dapat dapat dilihat pada Tabel 7. 
Tabel 7. Kebutuhan Air Rumah Tangga (Air Minum dan Memasak) di Desa Pulau Sarak

\begin{tabular}{clc}
\hline No. & Kebutuhan Air Domestik & Jumlah ((liter/ hari) /jiwa) \\
\hline 1. & Minum & 1,9 \\
2. & Memasak & 4,4 \\
& Total & 6,3 \\
\hline
\end{tabular}

Tabel 8. Jumlah Kebutuhan Air Rumah Tangga di Setiap Desa di Wilayah Kecamatan KamparTahun 2019

\begin{tabular}{|c|c|c|c|c|}
\hline \multirow[b]{2}{*}{ No. } & \multirow[b]{2}{*}{ Desa } & $P y$ & $d y$ & $Q y$ \\
\hline & & $\begin{array}{l}\text { jumlah pengguna air } \\
\text { (jiwa) }\end{array}$ & $\begin{array}{c}\text { standar kebutuhan air } \\
((\text { liter/hari/)jiwa) }\end{array}$ & kebutuhan air (liter/hari) \\
\hline 1 & Air Tiris & 6405 & 6,3 & 40.352 \\
\hline 2 & Batu Belah & 5058 & 6,3 & 31.865 \\
\hline 3 & Tanjung Berulak & 2241 & 6,3 & 14.118 \\
\hline 4 & Ranah & 3460 & 6,3 & 21.798 \\
\hline 5 & Penyasawan & 5428 & 6,3 & 34.196 \\
\hline 6 & Rumbio & 3331 & 6,3 & 20.985 \\
\hline 7 & Padang Mutung & 2836 & 6,3 & 17.867 \\
\hline 8 & Pulau Jambu & 1557 & 6,3 & 9.809 \\
\hline 9 & Tanjung Rambutan & 2362 & 6,3 & 14.881 \\
\hline 10 & Simpang kubu & 2508 & 6,3 & 15.800 \\
\hline 11 & Naumbai & 2023 & 6,3 & 12.745 \\
\hline 12 & Limau Manis & 2168 & 6,3 & 13.658 \\
\hline 13 & Ranah Singkuang & 1144 & 6,3 & 7.207 \\
\hline 14 & Ranah Baru & 1119 & 6,3 & 7.050 \\
\hline 15 & Bukit Ranah & 2091 & 6,3 & 13.173 \\
\hline 16 & Pulau Sarak & 1707 & 6,3 & 10.754 \\
\hline 17 & Pulau Tinggi & 1756 & 6,3 & 11.063 \\
\hline \multirow[t]{2}{*}{18} & Koto Tibun & 2123 & 6,3 & 13.375 \\
\hline & Total & 49317 & 6,3 & 310.697 \\
\hline
\end{tabular}

Tabel 8 menjelaskan jumlah kebutuhan air rumah tangga setiap desa yang ada di Kecamatan Kampar Tahun 2019 bahwa perhitungan kebutuhan air rumah tangga diperoleh dari hasil perhitungan antara kebutuhan air rumah tangga dengan jumlah penduduk. Hasil kebutuhan air rumah tangga setiap desa yang ada di Kecamatan Kampar Tahun 2019 dibandingkan dengan debit harian Mata Air Sikumbang dapat dilihat pada Tabel 9.

Tabel 9. Debit Harian Mata Air Sikumbang dan Kebutuhan Air Rumah Tangga di Kecamatan

\begin{tabular}{clcc}
\multicolumn{4}{c}{ Kampar Tahun 2019} \\
\hline No. & \multicolumn{1}{c}{ Bulan } & Debit Harian (liter/hari) & kebutuhan air rumah tangga (liter/hari) \\
\hline 1. & Maret 2019 & 685.440 & 310.697 \\
2. & April 2019 & 806.400 & 310.697 \\
3. & Mei 2019 & 732.960 & 310.697 \\
4. & Juni 2019 & 862.560 & 310.697 \\
5. & Juli 2019 & 715.680 & 310.697 \\
6. & Agustus 2019 & 648.000 & 310.697 \\
7. & September2019 & 757.440 & 310.697 \\
8. & Oktober 2019 & 892.800 & 310.697 \\
9. & November 2019 & 1.010 .880 & 310.697 \\
10. & Desember 2019 & 970.560 & 310.697 \\
\hline
\end{tabular}

Grafik debit harian Mata Air Sikumbang dan kebutuhan air rumah tangga di Kecamatan Kampar Tahun 2019 sebagai berikut (Gambar 1) 


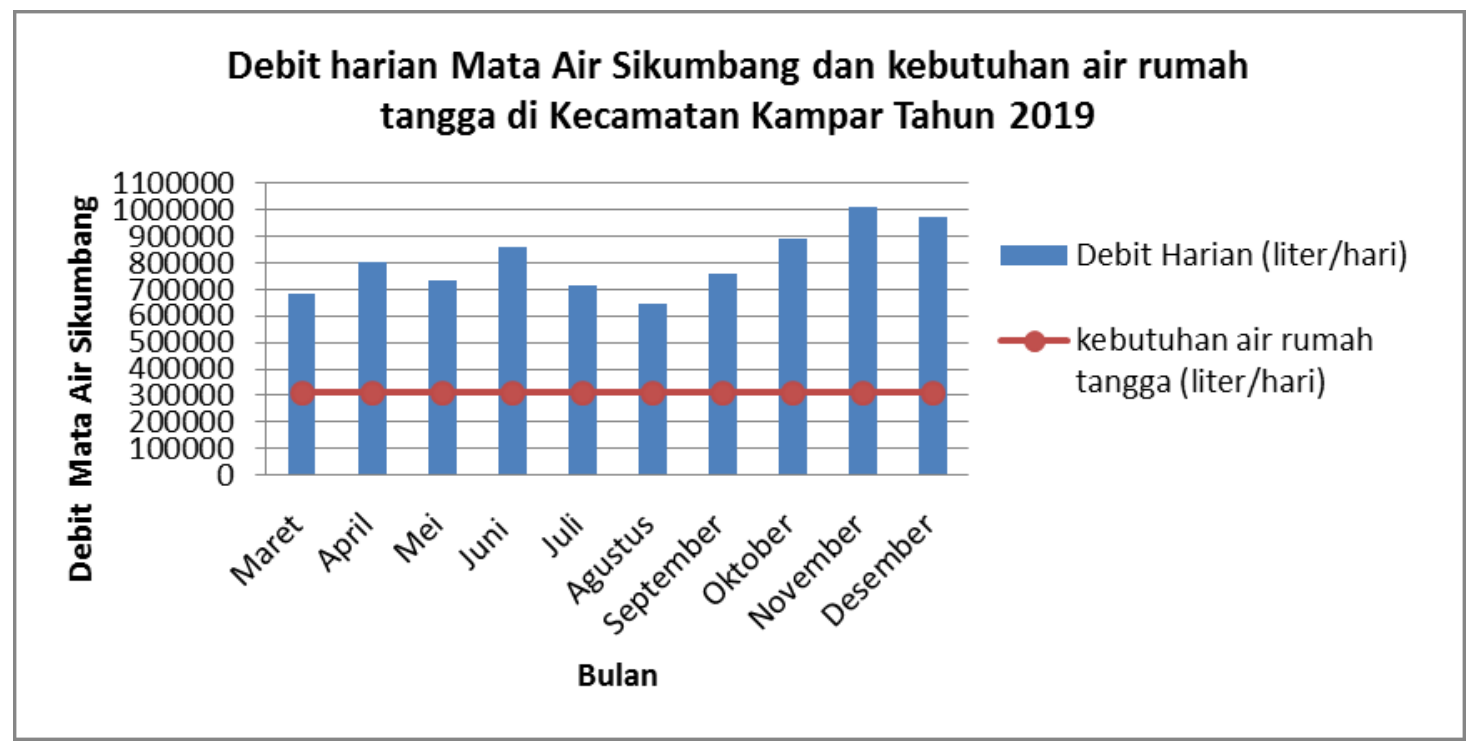

Gambar 1. Grafik Debit Harian Mata Air Sikumbang dan Kebutuhan Air Rumah Tangga di Kecamatan Kampar Tahun 2019

Dilihat dari Gambar 1 hasil pengukuran debit harian Mata Air Sikumbang pada setiap bulannya tidak terdapat penurunan debit secara signifikan dan berada di atas debit air untuk kebutuhan air rumah tangga di Kecamatan Kampar Tahun 2019. Hasil ini menunjukkan bahwa ketersediaan Mata Air Sikumbang mampu mencukupi kebutuhan air rumah tangga untuk setiap desa yang ada di kecamatan Kampar pada Tahun 2019.

Tabel 10. Proyeksi Kebutuhan Air Rumah Tangga Setiap Desa di Wilayah Kecamatan Kampar Tahun 2019, Tahun 2024, dan Tahun 2029

\begin{tabular}{|c|c|c|c|c|c|c|c|c|}
\hline \multirow{3}{*}{ No. } & \multirow{3}{*}{ Desa } & \multicolumn{7}{|c|}{ Proyeksi kebutuhan air rumah tangga setiap desa pada wilayah Kecamatan Kampar } \\
\hline & & \multicolumn{3}{|c|}{ Jumlah Penduduk } & \multirow{2}{*}{$\begin{array}{c}\text { Standar } \\
\text { kebutuhan } \\
\text { air rumah } \\
\text { tangga }\end{array}$} & \multicolumn{3}{|c|}{ Kebutuhan Air } \\
\hline & & 2019 & 2024 & 2029 & & 2019 & 2024 & 2029 \\
\hline 1 & Air Tiris & 6405 & 6459 & 6514 & 6,3 & 40352 & 40692 & 41038 \\
\hline 2 & Batu Belah & 5058 & 5121 & 5185 & 6,3 & 31865 & 32262 & 32666 \\
\hline 3 & Tanjung Berulak & 2241 & 2279 & 2318 & 6,3 & 14118 & 14358 & 14603 \\
\hline 4 & Ranah & 3460 & 3497 & 3534 & 6,3 & 21798 & 22031 & 22264 \\
\hline 5 & Penyasawan & 5428 & 5467 & 5506 & 6,3 & 34196 & 34442 & 34688 \\
\hline 6 & Rumbio & 3331 & 3373 & 3415 & 6,3 & 20985 & 21250 & 21515 \\
\hline 7 & Padang Mutung & 2836 & 2878 & 2920 & 6,3 & 17867 & 18131 & 18396 \\
\hline 8 & Pulau Jambu & 1557 & 1584 & 1611 & 6,3 & 9809 & 9979 & 10149 \\
\hline 9 & Tanjung Rambutan & 2362 & 2410 & 2460 & 6,3 & 14881 & 15183 & 15498 \\
\hline 10 & Simpang kubu & 2508 & 2563 & 2619 & 6,3 & 15800 & 16147 & 16500 \\
\hline 11 & Naumbai & 2023 & 2048 & 2074 & 6,3 & 12745 & 12902 & 13066 \\
\hline 12 & Limau Manis & 2168 & 2206 & 2245 & 6,3 & 13658 & 13898 & 14144 \\
\hline 13 & Ranah Singkuang & 1144 & 1175 & 1206 & 6,3 & 7207 & 7403 & 7598 \\
\hline 14 & Ranah Baru & 1119 & 1143 & 1168 & 6,3 & 7050 & 7201 & 7358 \\
\hline 15 & Bukit Ranah & 2091 & 2119 & 2147 & 6,3 & 13173 & 13350 & 13526 \\
\hline 16 & Pulau Sarak & 1707 & 1743 & 1779 & 6,3 & 10754 & 10981 & 11208 \\
\hline 17 & Pulau Tinggi & 1756 & 1792 & 1828 & 6,3 & 11063 & 11290 & 11516 \\
\hline \multirow[t]{2}{*}{18} & Koto Tibun & 2123 & 2165 & 2208 & 6,3 & 13375 & 13640 & 13910 \\
\hline & Total & 49317 & 50020 & 50732 & & 310697 & 315139 & 319643 \\
\hline
\end{tabular}


Tabel 11. Debit Harian Mata Air Sikumbang dan Proyeksi Kebutuhan Air Rumah Tangga Kecamatan Kampar Tahun 2019, Tahun 2024, dan Tahun 2029

\begin{tabular}{rlcccc}
\hline No. & \multicolumn{1}{c}{ Bulan } & $\begin{array}{c}\text { Debit Harian } \\
\text { (liter/hari) }\end{array}$ & $\begin{array}{c}\text { kebutuhan air } \\
\text { rumah tangga } \\
\text { Tahun 2019 } \\
\text { (liter/hari) }\end{array}$ & $\begin{array}{c}\text { kebutuhan air } \\
\text { rumah tangga } \\
\text { Tahun 2024 } \\
\text { (liter/hari) }\end{array}$ & $\begin{array}{c}\text { kebutuhan air } \\
\text { rumah tangga } \\
\text { Tahun 2029 } \\
\text { (liter/hari) }\end{array}$ \\
\hline 1. & Maret 2019 & 685.440 & 310.697 & 315.139 & 319.643 \\
2. & April 2019 & 806.400 & 310.697 & 315.139 & 319.643 \\
3. & Mei 2019 & 732.960 & 310.697 & 315.139 & 319.643 \\
4. & Juni 2019 & 862.560 & 310.697 & 315.139 & 319.643 \\
5. & Juli 2019 & 715.680 & 310.697 & 315.139 & 319.643 \\
6. & Agustus 2019 & 648.000 & 310.697 & 315.139 & 319.643 \\
7. & September2019 & 757.440 & 310.697 & 315.139 & 319.643 \\
8. & Oktober 2019 & 892.800 & 310.697 & 315.139 & 319.643 \\
9. & November 2019 & 1.010 .880 & 310.697 & 315.139 & 319.643 \\
10. & Desember 2019 & 970.560 & 310.697 & 315.139 & 319.643 \\
\hline
\end{tabular}

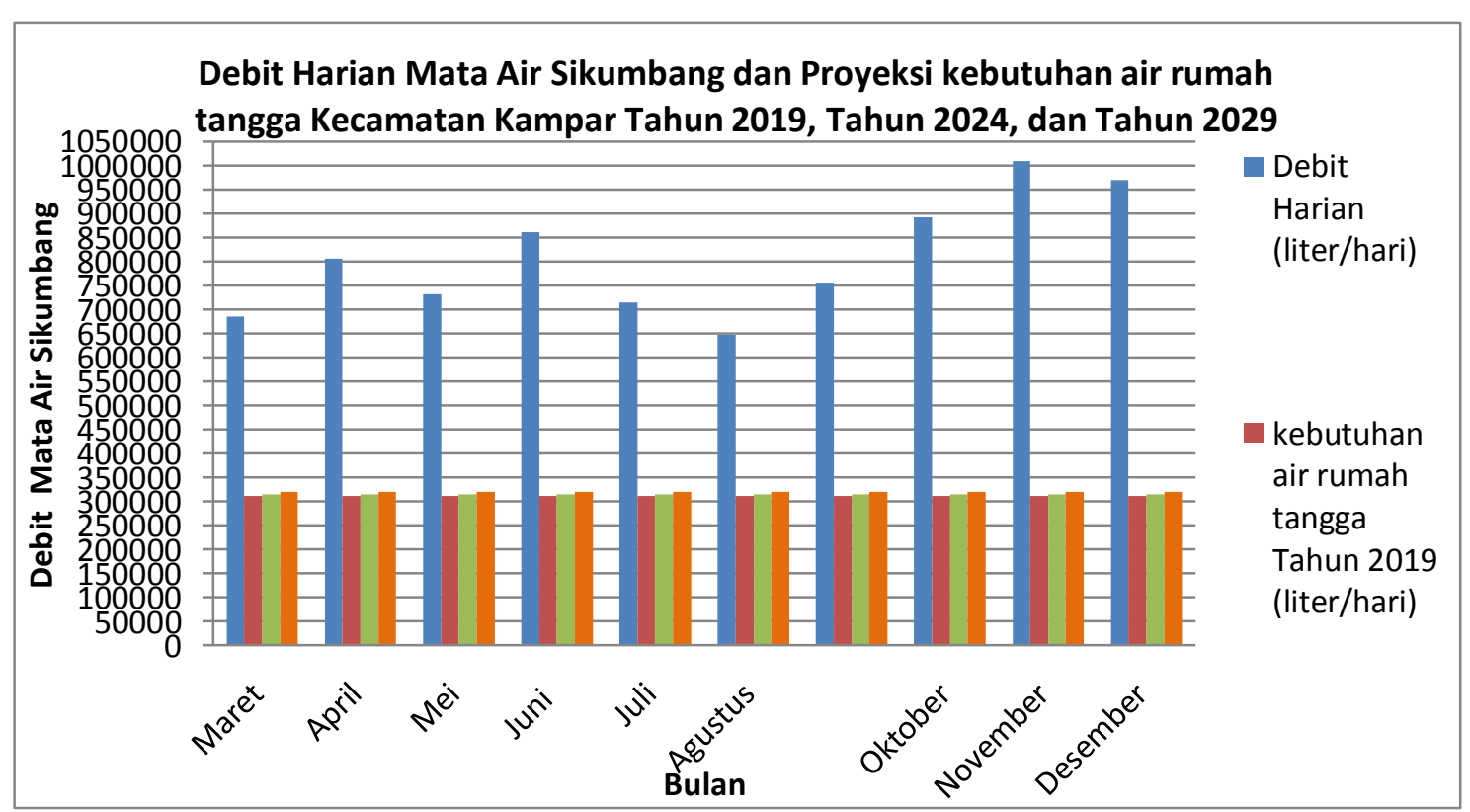

Gambar 2. Grafik Debit Harian Mata Air Sikumbang Dan Proyeksi Kebutuhan Air Rumah Tangga Kecamatan Kampar Tahun 2019, Tahun 2024, dan Tahun 2029

Dilihat dari Tabel 11 dan Gambar 2 menunjukkan bahwa jumlah ketersediaan air Mata Air Sikumbang pada Tahun 2019 dapat mencukupi untuk kebutuhan air rumah tangga di Kecamatan Kampar dalam kurun waktu sepuluh tahun yang akan datang. Pada Tahun 2029 ketersediaan air Mata Air Sikumbang masih dalam kondisi surplus.

\section{Strategi Pengelolaan Mata Air Sikumbang}

Penyusunan strategi pengelolaan Mata Air Sikumbang dilakukan menggunakan metoda SWOT (Sthrength, Weakness, Opportunity and Threats). Dalam metode ini terlebih dahulu dirumuskan faktorfaktor apa saja yang menjadi kekuatan, kelemahan, peluang dan ancaman dalam pengelolaan Mata Air Sikumbang. Setelah mengetahui faktor-faktor yang berpengaruh dalam pengelolaan tersebut, selanjutnya dilakukan pemberian bobot dan rating. Bobot dan rating dimaksudkan untuk mengetahui derajat kepentingan (bobot) dan derajat kuat tidaknya (rating) pengaruh indikator tersebut terhadap pengelolaan Mata Air Sikumbang. Nilai bobot merupakan nilai pengaruh dari indikator-indikator internal dan eksternal yang diberikan nilai dengan skala mulai dari 1 (tidak penting), 2 (agak penting), 3 (penting) dan 4 (sangat penting). Kemudian bagi nilai-nilai pengaruh tersebut dengan jumlah total nilai pengaruh untuk mendapatkan bobot, sehingga apabila semua bobot dijumlahkan maka hasilnya adalah 1 . Nilai rating merupakan nilai dari indikator-indikator internal dan eksternal dengan skala mulai dari 1 (tidak baik), 2 (agak baik), 3 (baik) dan 4 (sangat baik) berdasarkan kondisi yang ada. Nilai positif pada rating menunjukkan indikator tersebut merupakan kekuatan atau peluang bagi pengelolaan Mata Air Sikumbang.. Nilai negatif pada rating menunjukkan indikator tersebut merupakan kelemahan atau ancaman bagi pengelolaan Mata Air Sikumbang. Berdasarkan atas faktor-faktor strategi kondisi internal 
dan eksternal, maka didapat Matriks Faktor Strategi Internal (IFAS) dan Matriks Faktor Strategi Eksternal (EFAS) sesuai dengan Tabel 12 berikut

Tabel 12. Matriks Faktor Strategi Internal (IFAS) Pengelolaan Mata Air Sikumbang

\begin{tabular}{|c|c|c|c|c|c|c|}
\hline No. & Faktor Internal & Pengaruh & $\begin{array}{c}\text { Bobot } \\
\text { (penting) }\end{array}$ & $\begin{array}{l}\text { Rating } \\
\text { (kuat) }\end{array}$ & $\begin{array}{l}\text { Nilai } \\
\text { Total }\end{array}$ & Keterangan \\
\hline $\mathrm{A}$ & Kekuatan & & & & & \\
\hline 1 & $\begin{array}{l}\text { Ketersediaan } \quad \begin{array}{l}\text { Mata } \\
\text { Sikumbang sepanjang }\end{array} \text { tahun } \\
\text { sebagai sumber air bersih }\end{array}$ & 4 & 0.25 & 4 & 1,0 & $\begin{array}{l}\text { Pengaruhnya sangat penting } \\
\text { untuk keberlangsungan usaha } \\
\text { Mata Air Sikumbang }\end{array}$ \\
\hline 2. & $\begin{array}{l}\text { Adanya pengusaha Ketersediaan } \\
\text { Mata Air Sikumbang sebagai } \\
\text { penyedia air bersih }\end{array}$ & 4 & 0.25 & 3 & 0,75 & $\begin{array}{l}\text { Pengaruhnya sangat penting } \\
\text { untuk pengelolaan usaha Mata } \\
\text { Air Sikumbang }\end{array}$ \\
\hline 3. & $\begin{array}{l}\text { Harga Ketersediaan Mata Air } \\
\text { Sikumbang terjangkau oleh } \\
\text { masyarakat }\end{array}$ & 4 & 0.25 & 4 & 1,0 & $\begin{array}{l}\text { Pengaruhnya sangat penting } \\
\text { untuk mempermudah } \\
\text { masyarakat dalam memenuhi } \\
\text { kebutuhan rumah tangga }\end{array}$ \\
\hline \multirow[t]{3}{*}{4.} & \begin{tabular}{lccc} 
Adanya & dukungan & masyarakat \\
dalam & menjaga & \multicolumn{2}{c}{ keamanan } \\
kegiatan usaha & mata air \\
sikumbang & & &
\end{tabular} & 4 & 0.25 & 3 & 0,75 & 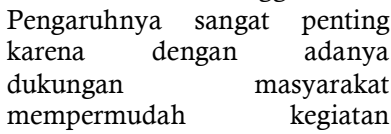 \\
\hline & & & & & & $\begin{array}{l}\text { pengelolaan } \quad \text { Mata } \\
\text { Sikumbang }\end{array}$ \\
\hline & Jumlah & 16 & 1 & 14 & 3.5 & \\
\hline B. & Kelemahan & & & & & \\
\hline 1. & $\begin{array}{l}\text { Beberapa sumber Mata Air } \\
\text { Sikumbang masih mengandung } \\
\text { koliform }\end{array}$ & 4 & 0,25 & -3 & $-0,75$ & $\begin{array}{l}\text { Sangat berpengaruh terhadap } \\
\text { penurunan kualitas Mata Air } \\
\text { Sikumbang }\end{array}$ \\
\hline 2. & $\begin{array}{l}\text { Jaringan distribusi yang masih } \\
\text { sedikit }\end{array}$ & 3 & 0,1875 & -2 & $-0,375$ & $\begin{array}{l}\text { Berpengaruh } \\
\text { pengelolaan, karena akan } \\
\text { memperlambat pendistribusian } \\
\text { Mata Air Sikumbang }\end{array}$ \\
\hline 3. & Kurangnya sarana dan prasarana & 3 & 0,1875 & -2 & $-0,375$ & $\begin{array}{l}\text { Berpengaruh dalam pengelolaan } \\
\text { karena dapat memperlambat } \\
\text { proses pendistributian }\end{array}$ \\
\hline 4 & $\begin{array}{l}\text { Pengetahuan pengelola dalam } \\
\text { hal teknik masih kurang }\end{array}$ & 3 & 0,1875 & -2 & $-0,375$ & $\begin{array}{l}\text { Berpengaruh dalam pengelolaan } \\
\text { Mata Air Sikumbang }\end{array}$ \\
\hline 5. & $\begin{array}{l}\text { Teknologi penyediaan Mata Air } \\
\text { Sikumbang yang kurang } \\
\text { memadai }\end{array}$ & 3 & 0,1875 & -2 & $-0,375$ & $\begin{array}{l}\text { Berpengaruh } \\
\text { menghasilkan Mata Air } \\
\text { Sikumbang yang berkualitas }\end{array}$ \\
\hline & Jumlah & 16 & 1 & -11 & $-2,25$ & \\
\hline & Jumlah Akhir & & & & 1,25 & \\
\hline
\end{tabular}

Tabel 13. Matriks faktor strategi eksternal (EFAS) pengelolaan Mata Air Sikumbang

\begin{tabular}{|c|c|c|c|c|c|c|}
\hline No. & Faktor Eksternal & Pengaruh & $\begin{array}{c}\text { Bobot } \\
\text { (penting) }\end{array}$ & $\begin{array}{l}\text { Rating } \\
\text { (kuat) }\end{array}$ & $\begin{array}{l}\text { Nilai } \\
\text { Total }\end{array}$ & Keterangan \\
\hline $\mathrm{A}$ & Peluang & & & & & \\
\hline 1. & $\begin{array}{l}\text { Permintaan masyarakat yang terus } \\
\text { meningkat terhadap Mata Air } \\
\text { Sikumbang }\end{array}$ & 4 & 0.27 & 4 & 1,1 & $\begin{array}{l}\text { Pengaruhnya sangat penting. } \\
\text { Meningkatnya pertumbuhan } \\
\text { penduduk maka kebutuhan air } \\
\text { semakin meningkat }\end{array}$ \\
\hline 2. & Segmentasi pelanggan yang luas & 3 & 0.2 & 3 & 0,6 & $\begin{array}{l}\text { Pengaruhnya penting dalam } \\
\text { pengembangan usaha Mata Air } \\
\text { Sikumbang }\end{array}$ \\
\hline 3. & Terbukanya lapangan pekerjaan & 4 & 0.27 & 4 & 1,1 & $\begin{array}{l}\text { Pengaruhnya sangat penting dalam } \\
\text { membuka lapangan pekerjaan bagi } \\
\text { masyarakat }\end{array}$ \\
\hline 4. & Pertumbuhan ekonomi masyarakat & 4 & 0.27 & 3 & 0,8 & $\begin{array}{l}\text { Pengaruhnya sangat penting dalam } \\
\text { meningkatkan } \\
\text { masyarakat }\end{array}$ \\
\hline & Jumlah & 15 & 1 & 12 & 3,6 & \\
\hline B. & Ancaman & & & & & \\
\hline 1. & $\begin{array}{l}\text { Belum adanya kelembagaan } \\
\text { pengelolaan Mata Air Sikumbang }\end{array}$ & 4 & 0,29 & -3 & $-0,87$ & $\begin{array}{l}\text { Berpengaruh dalam pengelolaan agar } \\
\text { pengloaan yang dilakukan dapat } \\
\text { terkontrol dan diawasi }\end{array}$ \\
\hline 2. & $\begin{array}{l}\text { Kurangnya kegiatan masyarakat } \\
\text { dalam pelestarian lingkungan }\end{array}$ & 3 & 0,21 & -2 & $-0,42$ & $\begin{array}{l}\text { Berpengaruh dalam menjaga kualitas } \\
\text { Mata Air Sikumbang }\end{array}$ \\
\hline 3. & $\begin{array}{l}\text { Belum adanya aturan hukum dasar } \\
\text { pengelolaan Mata Air Sikumbang }\end{array}$ & 4 & 0,29 & -2 & $-0,87$ & $\begin{array}{l}\text { Berpengaruh dalam pengelolaan } \\
\text { untuk menjaga kelestarian Mata Air } \\
\text { Sikumbang }\end{array}$ \\
\hline 4 & Kurangnya perhatian pemerintah & 3 & 0,21 & -2 & $-0,42$ & $\begin{array}{l}\text { Berpengaruh dalam pengembangan } \\
\text { usaha dan investasi Mata Air } \\
\text { Sikumbang }\end{array}$ \\
\hline & Jumlah & 14 & 1 & -11 & $-2,58$ & \\
\hline & Jumlah Akhir & & & & 1,02 & \\
\hline
\end{tabular}




\section{ZONA}

Jurnal Lingkungan

ISSN : 2502-6496 (Print)

Berdasarkan Tabel 12 dan Tabel 13, jumlah nilai akhir indikator strategi internal (kekuatan dan kelemahan) pengelolaan Mata Air Sikumbang adalah 1,25 atau dalam kondisi kuat, sedangkan nilai total indikator strategi eksternal (peluang dan ancaman) adalah 1,02 atau dalam kondisi memiliki peluang. Posisi ini bila digambarkan dalam kuadran adalah termasuk kuadran I. Selengkapnya dapat dilihat pada Gambar berikut.

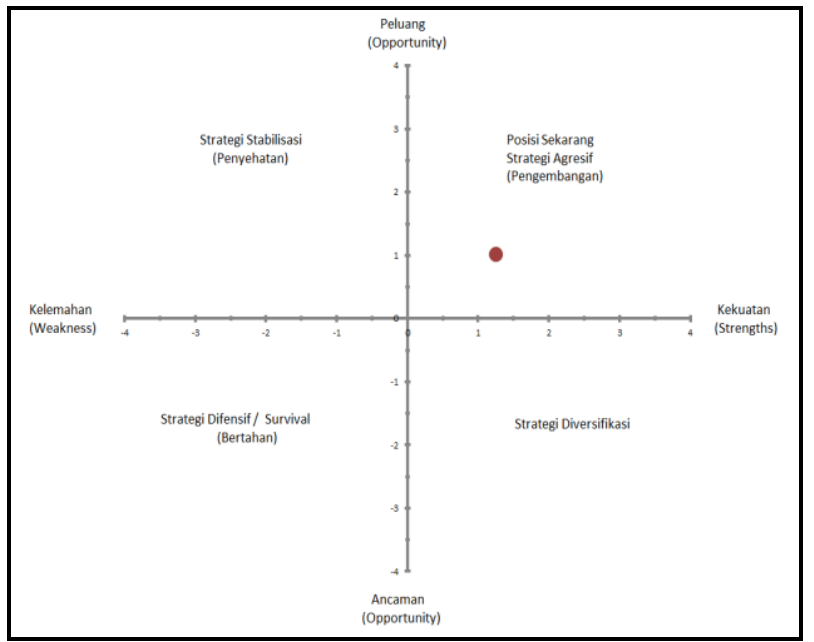

Gambar 3. Kuadran Strategi Pengelolaan Mata Air Sikumbang

Pada Gambar 3 terlihat bahwa posisi untuk melakukan strategi pengelolaan Mata Air Sikumbang adalah pada kuadran I. Pada posisi ini rekomendasi strategi yang dapat diambil adalah strategi agresif atau juga disebut strategi pengembangan. Setelah didapat rekomendasi strategi, langkah selanjutnya adalah menyusun rumusan strategi pengembangan berdasarkan Matrik Analisis SWOT, yaitu strategi yang dibangun berdasarkan komponen strategi kekuatan dan peluang. Setelah mengidentifikasi faktor internal dan eksternal yang menjadi kekuatan dan kelemahan serta peluang dan ancaman dalam pengelolaan Mata Air Sikumbang, maka dengan menggunakan analisis matriks SWOT diperoleh beberapa alternatif strategi pengelolaan Mata Air Sikumbang tersebut adalah strategi pengembangan dengan memanfaatkan kekuatan (Strength) dan peluang (Opportunities) yang ada.

Strategi S-O yang menggunakan kekuatan internal dan memanfaatkan peluang eksternal dengan cara:

1. Mengoptimalkan fungsi utama Mata Air Sikumbang sebagai sumber air bersih dalam memenuhi kebutuhan air rumah tangga. Mengoptimalkan sumber daya Mata Air Sikumbang untuk peningkatan jumlah penjualan dengan menambah perluasan daerah penjualan dengan memanfaakan peluang pasar yang ada sehingga dengan adanya sumber daya Mata Air Sikumbang masyarakat dapat memenuhi kebutuhan air rumah tangganya.

2. Meningkatkan sistem pemasaran Mata Air Sikumbang sehingga terbukanya lapangan pekerjaan yang baru dan dapat meningkatkan pertumbuhan ekonomi masyarakat. Menambah distribusi pasar yang diambil dapat memanfaatkan peluang dengan akses pengangkutan yang baik. Salah satu cara yang dapat ditempuh yaitu dengan menambah agen Mata Air Sikumbang di daerah lain.

3. Peningkatan peran serta masyarakat dalam menjaga dan melestarikan sumber Mata Air Sikumbang.

\section{KESIMPULAN}

Berdasarkan hasil penelitian dan analisa data yang telah dilakukan maka dapat disimpulkan sebagai berikut:

1. Potensi Mata Air Sikumbang berdasarkan nilai debitnya dari bulan Maret sampai Desember Tahun 2020 adalah sebesar 247.127.040 liter. Kebutuhan air bersih untuk kebutuhan rumah tangga (air minum dan memasak) di kecamatan Kampar adalah sebesar 6,3 ((liter/hari)/jiwa), sehingga kebutuhan air masyarakat di kecamatan Kampar Tahun 2019 adalah 310.697 liter/hari. Rata-rata debit harian Mata Air Sikumbang adalah sebesar 808.272 liter/hari. Perhitungan dari rata-rata debit harian Mata Air Sikumbang menunjukkan bahwa nilai debit Mata Air Sikumbang melebihi nilai kebutuhannya.

2. Berdasarkan hasil analisis SWOT terhadap pengelolaan Mata Air Sikumbang, maka strategi yang dapat diterapkan adalah startegi agresif (pengembangan) yaitu memaksimalkan kekuatan dan memanfaatkan peluang yang ada, sehingga meminimalisir kelemahan dan menghindari ancaman. pengelolaan Mata Air Sikumbang haruslah mengoptimalkan fungsi utama Mata Air Sikumbang sebagai sumber air bersih 
dalam memenuhi kebutuhan air rumah tangga dan meningkatkan sistem pemasarannya. Peran masyarakat dalam menjaga dan melestarikan sumber Mata Air Sikumbang juga perlu ditingkatkan.

\section{DAFTAR PUSTAKA}

Agus, N D P., E E. Nurlalelih dan Sitawati. 2015. Evaluasi Pemilihan Jenis dan Penataan Tanaman Asdak, C. 2007. Hidrologi dan Pengelolaan Daerah Aliran Sungai. Gajah Mada University Press. Yogyakarta

Badan Pusat Statistik Provinsi Riau .2017. Provinsi Riau Dalam Angka 2017. BPS Provinsi Riau. Pekanbaru

Haumahu, J.P. 2011. Kualitas Kimia Air Tanah di Kota Piru Kabupaten Seram Bagian Barat. Jurnal Budidaya Pertanian 7 (2) : 72-78.

Hidayat, T. 2015. Potensi Dan Pemanfaatan Mata Air Sikumbang Desa Pulau Sarak Pada Kawasan Hutan Larangan Adat Rumbio Kampar-Riau. Jurnal Wahana Forestra 10 (1) : 41-53

Kartasapoetra, A.G. 2004. Klimatologi : Pengaruh Iklim terhadap Tanah dan Tanaman. Bumi Aksara. Jakarta.

Kodoatie, R.J dan Sjarief, R. 2005. Pengelolaan Sumber Daya Air Terpadu. Andi, Yogyakarta.

Kodoatie, R.J dan Sjarief, R. 2010. Tata Ruang Air. Andi, Yogyakarta.

Kodoatie, R.J. 1996. Pengantar Hidrologi. Andi Press, Yogyakarta.

Matahelumual, B.C. 2010. Kajian Kondisi Air Tanah Jakarta. Jurnal Lingkungan dan Bencana Geologi $1(3): 131-149$

Menteri Kesehatan RI. 2002. Keputusan Menteri Kesehatan Republik Indonesia No. 907/ Menkes /SK / VII/ 2002 tentang Syarat-syarat dan Pengawasan Kualitas Air Minum. Kementerian Kesehatan. Jakarta.

Rangkuti, F. 2001. Analisis SWOT Teknik Membelah Kasus Bisnis. Gramedia Pustaka Utama. Jakarta.

Sugiyono. 2016. Metode Penelitian Kuantitatif, Kualitatif, dan R \&D. Alfabeta. Bandung

Wibowo, S. 2007. Manajemen Air Tanah berbasis Cekungan Air Tanah. Jurusan Teknik Sipil Fakultas Teknik Universitas Diponegoro. Semarang.

Widodo, E. 2017. Analisa Pengaruh Variasi Diameter Pipa Tekan Pvc Pada Pompa Aksial Untuk Kecepatan Gaya Dorong Air. Jurnal Rekayasa Energi Manufaktur 2(1) : 37-43.

Winasari, K. 2015. Uji Bakteriologis Air Minum pada Mata Air Bukit Sikumbang Desa Pulau Sarak Kecamatan Kampar. JOM FK 2 (2) :1-7 